\title{
What you need to know about imaging the liver
}

\section{A practical review of current literature}

\author{
Gaurav Bhattacharya (MD), Michael Kabiri (MD), Laura Callan (Meds 2015) \\ Faculty Reviewer: Dr Michael Lock, MD, CCFP, FCFP, FRCPC Chair (Department of Oncology, Division of Radiation Oncology)
}

\begin{abstract}
Hepatic cancers are an increasing source of morbidity and mortality in the developing and the developed world. In this paper, we highlight the current imaging modalities used for various cystic and solid hepatic lesions. The rationale behind selection of these modalities and an efficient evidence based step by step diagnostic algorithm are presented. Emphasis is placed on both identifying as well as differentiating between a benign, primary malignant and metastatic lesion.
\end{abstract}

\section{BACKGROUND}

Cancer of the liver remains one of the most common causes of cancer as well as cancer deaths worldwide ${ }^{1}$ and is responsible for about three quarters of a million deaths each year. While primarily concentrated in the developing world, the incidence is rising rapidly in developed countries. This includes Canada, where it has more than doubled over the last forty years. ${ }^{2}$ In North America, this ongoing rising incidence is due to increased prevalence of known underlying risk factors for liver cancer including the silent obesity related disease called non-alcoholic steatohepatitis (NASH), hepatitis $\mathrm{B}$ and $\mathrm{C}$, cirrhosis, as well as an aging population now entering a period of disease manifestation. Patients will present to physicians in many different specialties due to the often non-specific or incidental presentations of this group of malignancies. Early identification is critical to improved outcome and health care providers in various specialties need to become knowledgeable of the recent advances in imaging, adjuvant therapies as well as stricter follow-up protocols in a multidisciplinary environment that lead to an earlier identification of metastases to the liver. ${ }^{3,4}$ The table ${ }^{5,6}$ highlights the potential differentials for malignant hepatic lesions which need to be identified and differentiated from their benign counterparts.

\begin{tabular}{|c|c|}
\hline CYSTIC & Cystadenocarcinoma \\
\hline \multirow{10}{*}{ SOLID } & Squamous cell carcinoma \\
\hline & Carcinoma of ovaries/pancreas/colon/kidneys \\
\hline & Neuroendocrine \\
\hline & Hepatocellular carcinoma \\
\hline & Fibrolamellar carcinoma \\
\hline & Hepatoblastoma \\
\hline & Cholangiosarcoma \\
\hline & Angiosarcoma \\
\hline & Primary Lymphoma \\
\hline & Metastases \\
\hline
\end{tabular}

Noninvasive differentiation of the underlying etiology, including detection, characterization, staging and therapy monitoring, is the main task of modern imaging. Among the three major available diagnostic options (ultrasound [US], computed tomography [CT] and magnetic resonance imaging [MRI]), there exist several variations in technique that permit improvements in the ability to visualize lesions. For example, requisition for contrast-enhanced imaging during certain phases, dynamic contrast-enhanced imaging and respiratory gating can be instrumental for allowing clinicians to identify a lesion correctly. While detailed histories, physical examinations and biochemical markers remain vital in framing a complete picture, cross sectional imaging of lesions often plays the central role in determining the identity and management options of a lesion. Therefore, a clear, evidence-based and organized approach to ordering and interpreting imaging of the liver, as presented below and summarized in Figure $1,{ }^{7}$ is essential to clinical practice.

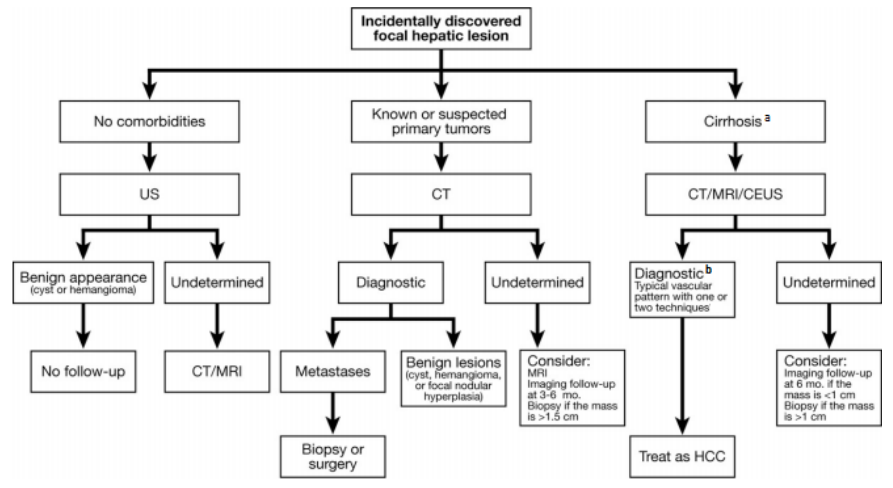

Figure 1: ${ }^{7}$ Suggested algorithm for the investigation of patients with incidental focal liver lesions. HCC, hepatocellular carcinoma.

${ }^{a}$ Diagnostic work-up of incidentally discovered hepatic lesions in patients with cirrhosis is based on the data-supported recommendations endorsed by the American Association for the Study of the Liver Diseases.

${ }^{b}$ Lesion enhancement during the hepatic arterial dominant phase, followed by washout during the hepatic venous phase and/or delayed phase as shown by a single (lesions $>2 \mathrm{~cm}$ ) or 2 (lesions $1-2 \mathrm{~cm}$ ) different imaging modalities.

\section{CYSTIC LESIONS}

Cysts are usually water-density, sharply demarcated lesions. The differential includes hemangiomas and malignant lesions. Figure 2 describes a standard imaging workup for identified cystic hepatic lesions. Traditionally, US has been the most economical modality for imaging the cancerous liver. ${ }^{8}$ While sensitivity and specificity with conventional sonography had lagged behind CT and MRI, with the advent of contrast-enhanced ultrasound (CEUS), these gaps, as detailed below, have shrunk greatly. CEUS also plays an important role in distinguishing premalignant cystadenoma and 


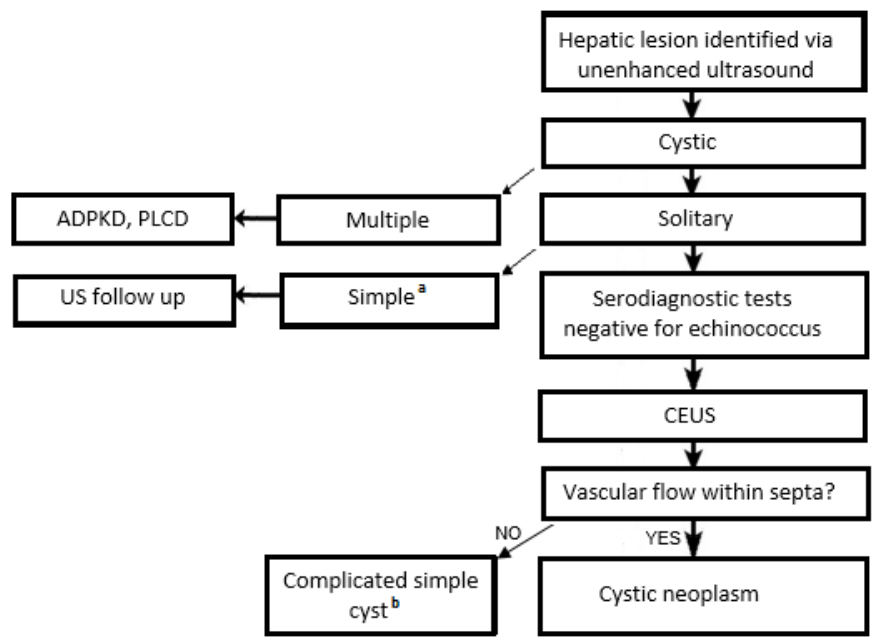

Figure 2: Algorithm highlighting cystic hepatic lesion imaging work up. PCLD: Polycystic liver disease; ADPKD: Autosomal dominant polycystic kidney disease. a Simple cyst US criteria: anechoic, aseptate, smooth sharp borders, strong posterior wall echoes, relative accentuation of echoes beyond the cyst. ${ }^{35}$

${ }^{\mathrm{b}}$ Complicated cyst as defined by compression, hemorrhage, or infection into a simple cyst. ${ }^{36}$

malignant cystadenocarcinoma from other complex cysts which feature similar characteristics. The former are characterized by vascular flow within the septa, which is absent in the latter. This technique is also useful in differentiating normal and common benign cystic lesions from malignant lesions. Cystic-appearing metastases, which may be manifestations of necrotic or cystic degenerations of rapidly growing tumours, and mucinous colonic or ovarian adenocarcinomas can be identified. ${ }^{9}$

A meta-analysis involving 45 studies and over 8000 focal lesions validates CEUS use for diagnostic workup with an overall $93 \%$ (95\% confidence interval [CI], 91-95\%) sensitivity and 90\% (95\% CI, 88-92\%) specificity for diagnosis of malignant liver lesions. ${ }^{10}$ Furthermore, the same study shows significantly better sensitivity for CEUS as compared to CT/ MRI with contrast and no significant difference in specificity between either modality. ${ }^{11}$ As CEUS remains the most economical solution, ${ }^{12-15}$ avoids radiation exposure, is available for bedside evaluation and usually involves much shorter wait times, US forms an ideal modality for the initial hepatic cancer diagnosis.

\section{SOLID LESIONS}

A standardized approach to image solid lesions has been developed (Figure 3) that relies on the different vascular anatomy of tumours and lesions. Solid hepatic lesions are imaged initially via triphasic abdominal CT with contrast. Imagers rely on the distinct pattern of contrast accumulation in three separate phases as the contrast enters the arterial system (Figure 4: arterial phase), then the venous system (early portal venous phase) and finally is excreted (late portal venous phase or washout phase). Briefly, tumours develop new abnormal arteries via a process called angiogenesis. Hepatic tumours derive the majority of their blood supply from the hepatic artery, while secondary lesions and the normal liver derive their blood supply mainly from the portal vein. Therefore, primary lesions "light up" in the arterial phase and maximally enhance the tumour. Respiratory motions can cause artifactual errors, but imaging of this phase can usually be achieved in a single breath-hold via multi detector CT (MDCT) ${ }^{16,17}$ after a bolus injection of contrast. ${ }^{18}$ Secondary lesions such as colorectal and other metastases tend to be isodense during the arterial phase and dark during the portal venous phase. The subsequent contrast washout in delayed phases provides further information useful for detection of smaller hepatocellular carcinoma (HCC) lesions. ${ }^{19.20}$

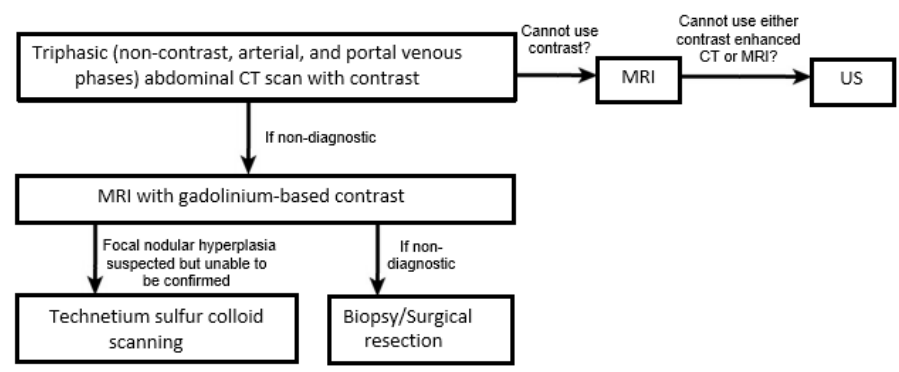

Figure 3: Algorithm highlighting solid hepatic lesion imaging work up. Note that unlike transabdominal US, intraoperative US involving direct placement of transducer up on liver parenchyma remains the most sensitive modality in identifying metastatic disease. $^{37}$

\section{HEPATOCELLULAR CARCINOMA AND INTRAHEPATIC CHOL- ANGIOCARCINOMA: A SPECIAL EMPHASIS}

As the most common type of liver cancer, HCC figures prominently in parts of the world where hepatitis remains endemic. Contrary to many other cancers, HCC does not mandate histologic confirmation for patients at high risk owing to the great accuracy of modern imaging modalities as well as the risks and side effects involved with liver biopsy. Indeed, pathologic diagnosis adds little to the diagnostic accuracy of imaging plus a blood test for alphafetoprotein, a liver tumour marker. In fact, a systemic review identified MRI and CT as the ideal diagnostic tests, particularly in cirrhotic patients. ${ }^{21}$ For now, use of positron emission tomography (PET) remains restricted to the detection of extrahepatic metastases and extrahepatic recurrence after liver transplantation, diagnosis or resection $^{22}$ and therefore will not be discussed further in this paper.

If a triphasic CT result is nondiagnostic, a gadolinium-enhanced MRI is recommended. ${ }^{23}$ The use of hepatobiliary-contrast-enhanced MRI not only allows for a better sensitivity and specificity in identification of the various lesions involved, ${ }^{24,25}$ but also provides additional information regarding liver function and the degree of cirrhosis. This allows for stratification of patients into early, intermediate and advanced tumour stages and can help facilitate choosing between aggressive and potentially curative versus life-extending, palliative and symptomatic treatments.

Aside from HCC, intraheptic cholangiocarcinoma (iCCA), with an increasing incidence worldwide,${ }^{26}$ is the most important malignant primary liver tumour differential due to its aggressive nature and dismal natural history. These tumours often present at an advanced stage and carry one of the highest mortality rates in oncology. Earlier detection is vital if patients are to be eligible 


\section{FEATURE ARTICLE}

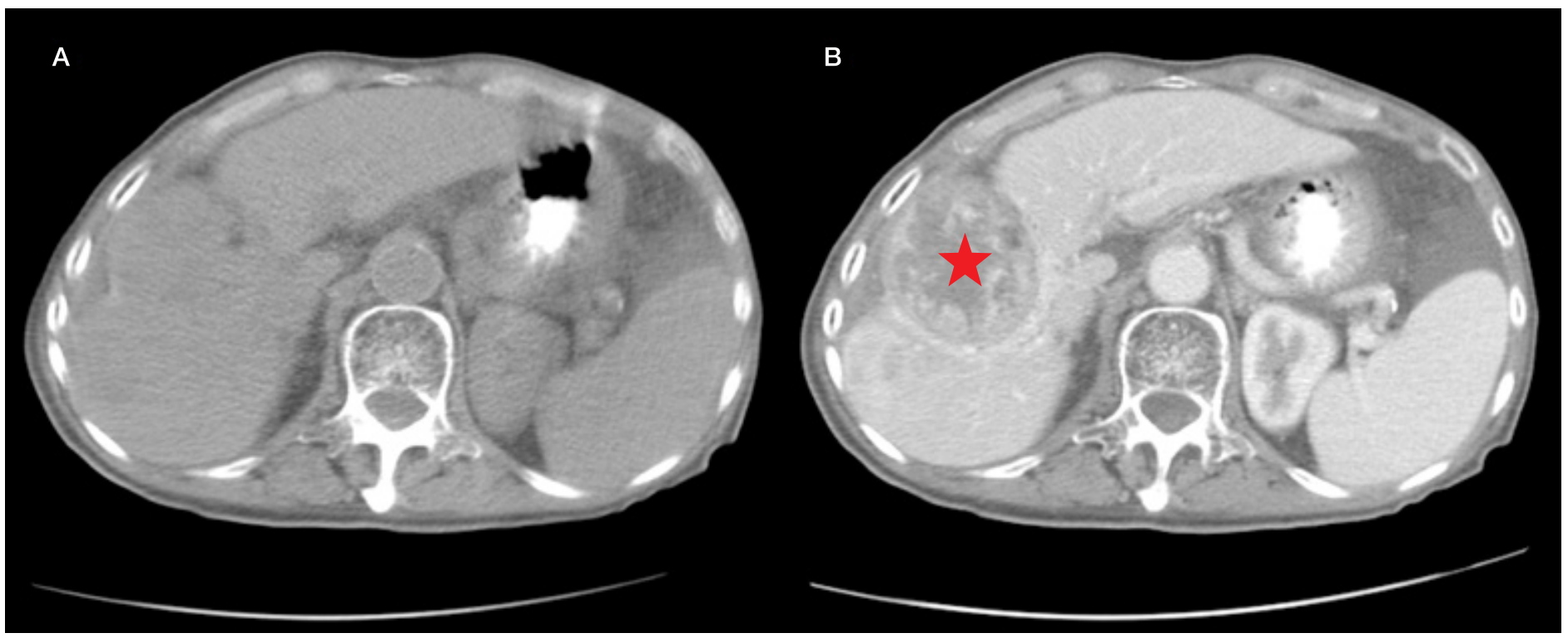

Figure 4: The impact of contrast in delineating a tumour. A, scout film. B, arterial phase axial CT image with tumour highlighted via a red star.

for aggressive treatments. Unlike HCC, which has a rapid uptake of contrast during the arterial phase and quick washout during the venous phase, iCCA has a progressive change in contrast during both phases. ${ }^{27}$ Other unique iCCA characteristic features include active inflammation at the tumour parenchymal interface leading to a rim pattern of peripheral enhancement and a slower contrast uptake due to extensive desmoplasia, caused by the proliferation of fibroblasts and fibroblastic tissue. ${ }^{28}$ However, biopsy still remains essential in most iCCA patients to confirm diagnosis.

\section{METASTASES}

For metastatic liver disease, the primary objective in oncology remains assessment of the resectability of the cancer. Such resection may be carried out either via surgery or through non surgical ablative therapies such as stereotactic body radiation therapy (SBRT) or radiofrequency ablation (RFA). Staging and successful planning is also critically affected by identification and subsequent removal of any potential extrahepatic disease as metastases to the chest and abdomen indicate poor prognosis and are contraindications to surgical resection. ${ }^{29}$

Repeated studies have shown the inferiority of transabdominal US to CT and MRI. ${ }^{30,31} \mathrm{CT}$ imaging remains the mainstay of staging and follow-up owing to several points. Firstly, CT permits excellent coverage of the entire abdomen and chest in a single session. Contrast-enhanced imaging allows for identification of both hypervascular metastases, such as those from renal cell, endocrine and some breast carcinomas (arterial phase), as well as hypovascular (portal venous phase) metastases, such as in colonic adenocarcinoma. ${ }^{32}$ CT also permits submillimeter-thickness slicing, allowing for the same spatial (isotropic) resolution in all directions. This provides the option of selecting an optimal image plane retrospectively regardless of initial angle of scanning and thereby enhances detection of smaller lesions. Speed and a lower cumulative period of radiation exposure remain important advantages. Newer 320 detector row CT (320 MDCT) can accomplish a whole liver scan in 0.35 seconds versus 25 to 30 seconds for single-slice helical CT. ${ }^{33}$

Finally, volumetric 3-dimensional rendering allows accurate segmental localization and delineation (unlike the aforementioned CEUS) and digital vascular reconstruction, leading to the creation of a 3D CT hepatic-mesenteric angiogram, thus obviating the need for extraneous angiography in presurgical planning. ${ }^{34}$

\section{SUMMARY}

The incidence of liver lesions has risen dramatically due to a plethora of underlying factors especially common in an aging population, such as cirrhosis, fatty liver and hepatitis. Since many patients present asymptomatically with liver incidentalomas, an early diagnosis, which is potentially crucial for therapy, may be dependent upon the assessment of the specialist outside of gastroenterology, hepatology or radiology. To facilitate an ideal guideline-based therapy, an evidence-based algorithmic approach is presented and the most common imaging modalities and the variations available to the clinician are described. The approach first begins with the identification of a lesion's cystic or solid nature. Then, ultrasound may be utilized for cystic lesions as it can differentiate benign "no touch" lesions (lesions where biopsy may cause significant complications and/or where imaging alone can make the diagnosis) such as hemangiomas, focal nodular hyperplasia, adenomas, aneurysms and aortoportal shunts from their biopsiable malignant counterparts such as neuroendocrine, ovarian and pancreatic carcinomas. For solid lesions, a separate algorithm is presented, beginning primarily with contrast-enhanced CT imaging, which helps identify the unique vascular signatures of lesions and thus distinguishes between primary malignancies (such as hepatocellular carcinoma), cholangiocarcinomas and liver metastases. 


\section{FEATURE ARTICLE}

\section{REFERENCES}

1. GLOBOCAN. Cancer Fact Sheet [Internet]. Geneva: World Health Organization; 2012 [cited 2014 Jan 7]. Available from: http://globocan.iarc.fr/Pages/fact_sheets_cancer.aspx

2. Roussy K. Liver cancer on the rise in Canada [Internet]. Toronto: CBC News; 2013 May 29 [cited 2013 Jul 17]. Available from: http://www.cbc.ca/news/health/liver-cancer-on-the-rise-incanada-1.1315831

3. Manfredi S, Lepage C, Hatem C, Coatmeur O, Faivre J, Bouvier A M. Epidemiology and management of liver metastases from colorectal cancer. Ann Surg. August 2006;244(2):254-9.

4. Pentheroudakis G, Fountzilas G, Bafaloukos D, Koutsoukou V, Pectasides D, Skarlos D, et al. Metastatic breast cancer with liver metastases: a registry analysis of clinicopathologic, management and outcome characteristics of 500 women. Breast Cancer Res Treat. 2006 Jun 1;97(3):237-44.

5. Lantinga MA, Gevers TJ, Drenth JP. Evaluation of hepatic cystic lesions. World J Gastroenterol. 2013 Jun 21;19(23):3543-54.

6. Bonder A, Afdhal N. Evaluation of liver lesions. Clin Liver Dis. 2012 May;16(2):271-83.

7. Marin D, Furlan A, Federle MP, Midiri M, Brancatelli G. Imaging approach for evaluation of focal liver lesions. Clin Gastroenterol Hepatol. 2009 Jun;7(6):624-34.

8. Song DS, Bae SH. Changes of guidelines diagnosing hepatocellular carcinoma during the last ten year period. Clin Mol Hepatol. 2012 Sep;18(3):258-67.

9. Torzilli G, Minagawa M, Takayama T, Inoue K, Hui AM, Kubota K, et al. Accurate preoperative evaluation of liver mass lesions without fine needle biopsy. Hepatology. 1999 Oct;30(4):889-93.

10. National Institute for Health and Care Excellence. NICE publishes guidance for ultrasound testing to diagnose liver cancer [Internet]. London: Nice Diagnostics Assessment Programme. 2012 [cited 2013 Jul 16]. Available from: http://www.nice.org. uk/newsroom/pressreleases/NICEPublishesGuidanceForUltrasoundTestingToDiagnoseLiverCancer.jsp

11. Friedrich Rust M, Klopffleisch T, Nierhoff J, Herrmann E, Vermehren J, Schneider MD, et al. Contrast-enhanced ultrasound for the differentiation of benign and malignant focal liver lesions: a meta analysis. Liver Int. 2013 May;33(5):739-55.

12. Westwood M, Joore M, Grutters J, Redekop K, Armstrong N, Lee K, et al. Contrast-enhanced ultrasound using SonoVue ${ }^{\circledR}$ (sulphur hexafluoride microbubbles) compared with contrast-enhanced computed tomography and contrast-enhanced magnetic resonance imaging for the characterisation of focal liver lesions and detection of liver metastases: a systematic review and cost-effectiveness analysis. Health Technol Assess. 2013 Apr;17(16):1-243.

13. Tranquart F, Correas JM, Ladam Marcus V, Manzoni P, Vilgrain V, Aube C, et al. Real-time contrast-enhanced ultrasound in the evaluation of focal liver lesions: diagnostic efficacy and economical issues from a French multicentric study. J Radiol. 2009 Jan;90(1 Pt 2):109-22.

14. Giesel FL, Delorme S, Sibbel R, Kauczor HU, Krix M. Contrast-enhanced ultrasound for the characterization of inciden- tal liver lesions - an economical evaluation in comparison with multi-phase computed tomography. Ultraschall Med. 2009 Jun;30(3):259-68.

15. Romanini L, Passamonti M, Aiani L, Cabassa P, Raieli G, Montermini I, et al. Economic assessment of contrast enhanced ultrasonography for evaluation of focal liver lesions: a multicentre Italian experience. Eur Radiol. 2007 Dec;17 Suppl 6:F99-106.

16. Xu LH, Cai SJ, Cai GX, Peng WJ. Imaging diagnosis of colorectal liver metastases. World J Gastroenterol. 2011 Nov 14;17(42):4654-9.

17. 1Hwang GJ, Kim MJ, Yoo HS, Lee JT. Nodular hepatocellular carcinomas: detection with arterial-, portal-, and delayed-phase images at spiral CT. Radiology. 1997 Feb;202(2):383-8.

18. Foley WD, Mallisee TA, Hohenwalter MD, Wilson CR, Quiroz FA, Taylor AJ. Multiphase hepatic CT with a multirow detector CT scanner. Ajr Am J Roentgenol. 2000 Sep;175(3):679-85.

19. Iannaccone R, Laghi A, Catalano C, Rossi P, Mangiapane F, Murakami T, et al. Hepatocellular carcinoma: role of unenhanced and delayed phase multi detector row helical CT in patients with cirrhosis. Radiology. 2005 Feb;234(2):460-7.

20. Moritz T, Prosch H, Schuster H, Ba Ssalamah A. Malignant focal liver lesions. Radiologe. 2011 Aug;51(8):697-703.

21. Bruix J, Sherman M, American Association for the Study of Liver Diseases. Management of hepatocellular carcinoma: an update. Hepatology. 2011 Mar;53(3):1020-2.

22. Colli A, Fraquelli M, Casazza G, Massironi S, Colucci A, Conte D, et al. Accuracy of ultrasonography, spiral CT, magnetic resonance, and alpha fetoprotein in diagnosing hepatocellular carcinoma: a systematic review. Am J Gastroenterol. 2006 Mar;101(3):513-23.

23. Campos JT, Sirlin CB, Choi JY. Focal hepatic lesions in Gd EOB DTPA enhanced MRI: the atlas. Insights Imaging. 2012 Oct;3(5):451-74.

24. Song MJ, Bae SH, Yoo IR, Park CH, Jang JW, Chun HJ, et al. Predictive value of $18 \mathrm{~F}$ fluorodeoxyglucose PET/CT for transarterial chemolipiodolization of hepatocellular carcinoma. World J Gastroenterol. 2012 Jul 7;18(25):3215-22.

25. Bruix J, Sherman M, Llovet JM, Beaugrand M, Lencioni R, Burroughs AK, et al. Clinical management of hepatocellular carcinoma. Conclusions of the Barcelona 2000 EASL conference. European Association for the Study of the Liver. J Hepatol. 2001 Sep;35(3):421-30.

26. European Association for Study of Liver, European Organisation for Research and Treatment of Cancer. EASL EORTC clinical practice guidelines: management of hepatocellular carcinoma. Eur J Cancer. 2012 Mar;48(5):599-641.

27. Bastati Huber N, Prosch H, Baroud S, Magnaldi S, Schima W, Ba Ssalamah A. New developments in MRI of the liver. Radiol. 2011 Aug;51(8):680-7.

28. Patel T. Worldwide trends in mortality from biliary tract malignancies. BMC Cancer. 2002 May 3;2:10.

29. Vilgrain V. Staging cholangiocarcinoma by imaging studies. HPB. 2008;10(2):106-9. 


\section{FEATURE ARTICLE}

30. Rimola J, Forner A, Reig M, Vilana R, de Lope CR, Ayuso C, et al. Cholangiocarcinoma in cirrhosis: absence of contrast washout in delayed phases by magnetic resonance imaging avoids misdiagnosis of hepatocellular carcinoma. Hepatology. 2009 Sep;50(3):791-8.

31. Razumilava N, Gores GJ. Classification, diagnosis, and management of cholangiocarcinoma. Clin Gastroenterol Hepatol. 2013 Jan;11(1):13-21.el; quiz e3-4.

32. Anderson CD, Rice MH, Pinson CW, Chapman WC, Chari RS, Delbeke D. Fluorodeoxyglucose PET imaging in the evaluation of gallbladder carcinoma and cholangiocarcinoma. J Gastrointest Surg. 2004 Jan;8(1):90-7.

33. Petrowsky H, Wildbrett P, Husarik DB, Hany TF, Tam S, Jochum W, et al. Impact of integrated positron emission tomography and computed tomography on staging and management of gallbladder cancer and cholangiocarcinoma. J Hepatol. 2006 Jul;45(1):43-50.

34. Yang J, Yan LN. Current status of intrahepatic cholangiocarcinoma. World J Gastroenterol Wjg. 2008 Nov 7;14(41):6289-97.

35. Fong Y. Surgical therapy of hepatic colorectal metastasis. CA Cancer J Clin. 1999 Aug;49(4):231-55.

36. Hagspiel KD, Neidl KF, Eichenberger AC, Weder W, Marincek B. Detection of liver metastases: comparison of superparamagnetic iron oxide enhanced and unenhanced MR imaging at 1.5 $\mathrm{T}$ with dynamic CT, intraoperative US, and percutaneous US. Radiology. 1995 Aug;196(2):471-8.

37. Robinson PJ. Imaging liver metastases: current limitations and future prospects. Br J Radiol. 2000 Mar;73(867):234-41.

38. Bernatik T, Strobel D, Hahn EG, Becker D. Detection of liver metastases: comparison of contrast enhanced wide band harmonic imaging with conventional ultrasonography. J Ultrasound Med. 2001 May;20(5):509-15.

39. Miller FH, Butler RS, Hoff FL, Fitzgerald SW, Nemcek AA Jr, Gore RM. Using triphasic helical CT to detect focal hepatic lesions in patients with neoplasms. Ajr Am J Roentgenol. 1998 Sep;171(3):643-9.

40. Sonoda A, Nitta N, Ushio N, Nitta Seko A, Tomozawa Y, Watanabe S, et al. 320 detector row computed tomography arteriography using $\mathrm{CO} 2$ gas to detect malignant liver tumors. Minim Invasive Ther Allied Technol. 2013 Apr;22(2):89-96.

41. Floriani I, Torri V, Rulli E, Garavaglia D, Compagnoni A, Salvolini L, et al. Performance of imaging modalities in diagnosis of liver metastases from colorectal cancer: a systematic review and meta analysis. J Magn Reson Imaging Jmri. 2010 Jan;31(1):19-31.

42. Wiering B, Krabbe PFM, Jager GJ, Oyen WJG, Ruers TJM. The impact of fluor 18 deoxyglucose positron emission tomography in the management of colorectal liver metastases. Cancer. 2005 Dec 15;104(12):2658-70.

43. Ke S, Zhang F, Wang W, Qiu X, Lin J, Cameron AG, et al. Multiple target specific molecular imaging agents detect liver cancer in a preclinical model. Curr Mol Med. 2012 Sep;12(8):94451.

44. Müller T, Mehrle S, Schieck A, Haberkorn U, Urban S, Mier W. Liver Imaging with a Novel Hepatitis B Surface Protein
Derived SPECT Tracer. Mol Pharm. 2013 Jun 3;10(6):2230-6.

45. Doherty JR, Trahey GE, Nightingale KR, Palmeri ML. Acoustic radiation force elasticity imaging in diagnostic ultrasound. Ieee Trans Ultrason Ferroelectr Freq Control. 2013 Apr;60(4):685701.

46. Lee DH, Lee JM, Klotz E, Kim SJ, Kim KW, Han JK, et al. Detection of recurrent hepatocellular carcinoma in cirrhotic liver after transcatheter arterial chemoembolization: value of quantitative color mapping of the arterial enhancement fraction of the liver. Korean J Radiol Off J Korean Radiol Soc. 2013 Feb;14(1):51-60.

47. Pokharel SS, Macura KJ, Kamel IR, Zaheer A. Current MR imaging lipid detection techniques for diagnosis of lesions in the abdomen and pelvis. Radiogr Rev Publ Radiol Soc North Am Inc. 2013 May;33(3):681-702.

48. Spiegel RM, King DL, Green WM. Ultrasonography of primary cysts of the liver. Ajr Am J Roentgenol. 1978 Aug;131(2):235-8.

49. Plard L, Guedin P, Le Pennec V, Chiche L. Hepatic cysts: diagnosis and management. J Chir (Paris). 2008 Jun;145(3):217-25. 